\title{
Migration Decisions Within Dual-Earner Partnerships: A Test of Bargaining Theory
}

This article focuses on the problems faced by dual-earner partnerships arising from the regional coordination of the partners' careers. It is still unknown whether the fact that couples are less mobile than singles is caused by homogeneous preferences within couples or by a process of balancing conflicting interests. Consequently, we analyze the potential conflicts provoked by work-related migration incentives. We test hypotheses derived from bargaining theory using quasi-experimental data from a factorial survey of nearly 280 European couples. Our results support the bargaining approach and confirm that asymmetrical shifts in bargaining power drive the potential for conflict. Women's willingness to move is generally less than men's, but the impact of employment prospects differs only slightly by gender.

School of Business and Economics, University of Erlangen-Nürnberg, Findelgasse 7/9, 90402 Nuremberg, Germany.

*Department of Sociology, University of Konstanz, Universitätsstr. 10, 78457, Konstanz, Germany.

**Department of Sociology, University of Konstanz, Universitätsstr. 10, 78457, Konstanz, Germany.

Key Words: bargaining theory, conflicting interests, dualearner partnerships, factorial survey design, household move.
It is well known that in modern societies, changing employment patterns affect couples in various ways. In particular, the increasing labor market participation of women leads to new challenges for couples living together. One of these challenges arises from the necessity to coordinate two careers in time and space. For example, the probability of migration drops significantly when people form a couple (McHugh, Gober, \& Reid, 1990; Quigley \& Weinberg, 1977). The migration literature offers a wide range of empirical findings as well as theoretical explanations regarding the determinants of household migration (Bartel, 1982; Bielby \& Bielby, 1992; Shauman \& Noonan, 2007). These findings, however, focus only on actual migration, not on the underlying considerations for or against a household move. As a consequence, there is inadequate knowledge regarding bargaining and conflicts within couples. Moreover, migration research based on "classic" survey data is usually biased toward the traditional case of men as the main breadwinners. Women who receive a job offer with a considerably higher salary than their male spouses are still rare (for Germany and the United States, see Cooke, 2006). Therefore, it is difficult to disentangle gender and structural effects on migration behavior.

Looking at household migration from a theoretical point of view, most researchers stress the necessity of considering the conflicting interests of the two partners. Especially in dual-earner 
couples, new job opportunities for one partner may correspond with decreasing opportunities for his or her mate. In line with this argument, one of the dominant theoretical models for analyzing dual-earner households is bargaining theory. In that framework, the partners have to bargain over (a) the decision for or against migration and (b) the arrangements that may follow after the household move. Although this theoretical model seems appropriate for the research problem at hand, there are astonishingly few empirical tests of it. One reason is the lack of paired data for couples that are necessary to observe the diverging interests of partners. Another limitation arises from focusing only on the results of the bargaining process. That is, theorists have tried to derive hypotheses regarding the shift of resources allocated to each partner and the consequences of that shift (Bernasco \& Giesen, 2000; Klasen, 1998; Lundberg \& Pollack, 1996). One of the main problems of this approach is the difficulty of empirically measuring the complete allocation of resources including immaterial resources such as love, emotional care, and recreational time.

In this article, we aim to fill these gaps by applying factorial survey analysis, a research design for combining survey research with an experiment. We requested that couples in Germany and Switzerland evaluate hypothetical descriptions of better employment opportunities in a distant location for one partner. This design gave us the opportunity to analyze to what extent moving preferences conflict within a partnership. By varying the hypothetical situations in an experimental manner, we were able to identify factors that influence the extent of potential conflicts arising from differing migration incentives. The aim was to complement the existing empirical knowledge on willingness to migrate within couples and to provide a direct test of bargaining models in family research.

\section{THEORETICAL FRAMEWORK}

\section{Bargaining Models}

In family research, bargaining models are often used to analyze allocation problems among household members and especially among spouses or cohabitation partners (Bitman, England, Folbre, Sayer, \& Matheson, 2003; Cooke, 2006; Lundberg \& Pollak, 1996). At the core of this theoretical framework is the situation in which two actors have to decide on the allocation of resources. These can refer to material resources, like household income, and to immaterial resources, such as the right to make decisions, enjoy leisure time, and avoid unpleasant household tasks. The result of this allocation decision depends on the relative bargaining power of each actor in the partnership.

This conceptual core can be found in different theoretical frameworks such as classical exchange theory (Blood \& Wolfe, 1960), social psychology (Thibaut \& Kelley, 1959), and rational choice theory (Manser \& Brown, 1980). The crucial question within all these approaches is the definition of relative power. Although there are some differences, most researchers agree that, to a large extent, the available alternatives to the current partnership determine each actor's bargaining power (England \& Farkas, 1986). The partner with better outside options has more power in the relationship because he or she can credibly threaten to leave the relationship. These outside options are also called threat points. Note that the bargaining process itself can stay implicit, that is, without any discussion between the partners, but it is assumed that both partners are aware of the power imbalance.

Although available alternatives may include the presence of other attractive partners (Bergstrom, 1996), in modern societies, a person's economic standing is probably the most decisive determinant of structural bargaining power in relationships. Labor market participation and an independent source of income make it possible for one partner to dissolve an unsatisfactory partnership. The next best alternative is often the move not into another relationship but into a single household. Moreover, the higher the persons' income, the more that easily that person should be able to find an attractive alternative partner. Thus, most research focused on labor market opportunities for measuring bargaining power in partnerships (Blau, Ferber, \& Winkler, 2001; Blood \& Wolfe, 1960; Ott, 1992).

\section{The Decision to Move the Household}

Within this theoretical framework, household moves can be seen as events that are likely to be affected by the relative bargaining power of exchange partners, and vice versa (Lundberg \& Pollak, 2003). As Mincer (1978) explained, it is unlikely that both partners will receive optimal job offers at the same time and within the same 
region. Consequently, a couple has to decide whether the migration incentive for one partner (the mover) is sufficient for accepting, at least temporarily, a worse employment situation for the other.

Mincer (1978) coined the term tied mover for a partner who experiences individual disadvantages by a move that is generally beneficial for the household. In contrast, a tied stayer forgoes the better job because his or her individual gains will not be sufficient to compensate for the overall household loss. In Mincer's classical model the actors will accept any individual loss as long as the household utility is maximized. Thus, this model fails to recognize the conflicts that result from the clash of individual interests between the partners.

From a dynamic bargaining point of view, even a higher household utility may not be sufficient for a potential tied mover to accept the migration. This is because, in the bargaining theoretical framework, it is expected that the actors rationally anticipate future allocations. More concretely, the actors are assumed to consider how a new situation affects their relative bargaining power and thereby their individual benefit of a move. Under the assumption that the bargaining power is mainly influenced by the employment and income possibilities of the actors, by definition, a tied mover will experience a loss of relative power. If this loss is too high, the tied mover may get even a lower level of household resources at the new destination than he or she had before the move, although the overall household resources are increased by the move (Lundberg \& Pollak, 2003). Thus, potential tied movers may reject the household move, whereas tied stayers may use their job offer to renegotiate the allocation of resources at the present location. The job offer can be seen as a new outside option because, theoretically, the tied stayer has an attractive alternative to the relationship consisting of the possibility of moving without the partner.

Bargaining models were most often used to predict the allocation of resources in a relationship (for a review, see Lundberg \& Pollak, 1996). In our opinion, however, measuring only the results of the bargaining process (e.g., shares of family income used for "private" consumptions, the distribution of leisure times and cumbersome household tasks) is not the most promising strategy to test this kind of theory. First, additional factors that are difficult to control for may influence the actual allocation of resources and duties (e.g., individual preferences). Second, and more important, actors try to solve these kinds of cooperation problems using various mechanisms. These can be joint investments in the relationship such as children, formal marriage contracts, and further commitments that settle mutual rights and obligations (Bernasco \& Giesen, 2000; Ott, 1992). Relation-specific investments enhance the interdependence of partners by increasing the sunk costs of the current relationship and thereby promoting further commitment that stabilizes the (trust in the) stability of the partnership (Brines \& Joyner 1999). Nonbinding agreements, in contrast, are considered insufficient. In intimate relationships, partners may (and often do) promise that, because of love, even if there is a shift in bargaining power, no renegotiation of resources will take place. But it is doubtful whether this promise is credible; it is well-known that love is no guarantee against conflict in marriage or cohabitation. These mechanisms are not captured when only the results of bargaining are considered.

\section{The Influence of Gender}

Bargaining models are, in principal, gender neutral, and this is the point that mostly arouses criticism (for the literature on migrations, see Bielby \& Bielby, 1992; Jürges, 2005). Different income options influence the bargaining process, and of course, income opportunities differ by gender. But after controlling for those structural factors and for the outside options in general, the willingness to move is expected to be no longer gender dependent. A gendered perspective, in contrast, suggests that the bargaining process also contributes to the production of gender; in other words, it leads individuals to affirm their categorical status of male or female (the process of doing gender) (see Fenstermaker, 2002; West \& Zimmerman, 1987). Even if doing gender clearly means more than "[living] up to normative conceptions of femininity or masculinity" (West \& Zimmerman, 1987, p. 136), gender-appropriate behavior should tend to, at least in general, be in line with culturally approved standards. Therefore, the decision-making process is expected to differ by gender especially if the actor's structural positions are incongruent with the gender norms (Hook \& Chalsani, 2008). Because these 
institutionalized norms still assign the main responsibility for the household income to the male partner (Huppe \& Cyr, 1997; Stickney \& Konrad, 2007; Szinovacz \& Harpster, 1993), the male's employment options are more likely to take priority over the female's ones in decisions.

Empirically, the relative impact of the two alternative explanations - bargaining versus subscription to gender norms - is still an unresolved issue (Blackburn, 2006; Lichter, 1983; Maxwell, 1988; Mincer, 1978; Spitze, 1984). By reason of data limitations, it was difficult to decide whether gender disparities in household decision making resulted from employment variables that were not controlled for and therefore corresponded with a gender-neutral bargaining process or whether they reflected normative expectations. The classifications of occupations typically used were too broad to capture the specific job and labor market characteristics that were unevenly distributed by gender (e.g., geographic ubiquity, length of career ladders) (see Shauman \& Noonan, 2007). Thus, most results were in line with both theoretical approaches. Our experimental design provided men and women with exactly the same employment opportunities, which we explain in more detail below. This may help provide insight into the gender influence on migration decisions.

\section{Hypotheses}

The bargaining model allows us to derive several hypotheses regarding how actors make migration decisions in dual-earner relationships. When evaluating a migration opportunity, the partners consider the expected changes in relative bargaining power. If the actors anticipate shifts in bargaining power and if there is any interest in preserving the relationship, they will be less willing to move if one of them will be worse off at the new destination. This leads to our first hypothesis:

Hla: Individual willingness to move will depend not only on the changes in one's own situation but also on the changes in the partner's situation.

Results in favor of the first hypothesis constitute, of course, only weak evidence for the bargaining model because altruism could also explain this phenomenon. Altruistic actors care about the future situation of their partners; hence, they will take into account potential disadvantages for their partners. The bargaining approach, however, additionally suggests that every actor will consider his or her own situation more important than his or her partner's situation. Any consideration of one's partner's interests will be in vain if the partnership fails in the future. The risk of a future separation and the interest in receiving a favorable position in the resource allocation lead to a primary interest in preserving one's own bargaining power. Therefore, we can hypothesize that no matter who has the better option, the change in one's own bargaining power is a stronger predictor of the willingness to move than is the respective change in the partner's power.

H1b: Actors' willingness to move is influenced more by their own options than those of their partners.

The general hypothesis regarding a couple's conflict potential is straightforward. All unexpected options to improve the relative bargaining power of one partner will question the negotiated arrangements and evoke clashing interests. The partner with the potential improvement is interested to move, whereas the other will reject the move to preserve the actual power balance. We term this clashing interest conflict potential because the partners may be able to actually resolve the conflict (see also Miller, Perlman, \& Brehm, 2007).

H2: An actor's potential increase in relative bargaining power due to a possible migration will lead to a higher conflict potential in the partnership.

Note that, to our knowledge, this is a new hypothesis derived from bargaining theory that has yet to be tested.

As outlined above, there are many reasons couples may differ in how they resolve the conflict, which may result from, for example, certain psychological characteristics of the partners. As sociologists, we are more interested in structural factors. One type of solution arises from the strength of each actor's commitment to the partnership (Nock, 1995). A credible commitment in this sense increases the threshold for leaving the partnership and therefore decreases an actor's bargaining power by reducing the utility of outside options. In families and relationships, there are three main types of mutual commitment: marriage, children, and common property 
(especially home ownership). We hypothesize that all three types of commitment lead to a lower level of conflict potential.

H3a: The conflict potential will be lower for couples who (a) are married, (b) have children, or (c) hold real estate property than for couples without these characteristics.

Couples also differ with respect to the time they have had to learn about each other and the relationship. Learning about each other's characteristics and preferences allows partners to assess each other's future behavior. Consequently, the joint history represents a proxy for mutual commitment that is not easily captured, such as learning to participate in and appreciate each other's hobbies. In addition, the duration of partnership might reflect a positive selection process: Partnerships in which mutual expectations were more often fulfilled and in which therefore greater trust has been established will have a lower risk of breakdown. This grown knowledge of each other and amount of commitment might cause a belief that, all else being equal, no renegotiation of resources after the move will take place.

H3b: The conflict potential declines with the duration of the partnership.

Finally, we consider the effect of gender on our research question. In the bargaining framework, gender should matter only to the extent that one gender tends to have less bargaining power because of structurally worse outside options. A gendered perspective in contrast suggests that, even when female partners have strong incentives to move, they may favor their male partners' careers to conform to normative gender ideologies.

H4: Female partners are less willing than their male partners to move in response to their own labor market options.

That is, we suppose an interaction effect of gender and labor market options on the willingness to move.

\section{METHOD}

The insufficient empirical research on the bargaining model in the field of families and couples is mainly caused by a lack of adequate data.
Existing survey data provided little or no information on the long-term career prospects and labor market situations at potential destinations (Shauman \& Noonan, 2007). Because of the low numbers of moving households, it was difficult to observe the shifts in resources allocations caused by household moves. Another problem is the high selectivity of migration: Persons with job-related migrations are generally more career oriented and professionally successful than immobile persons, so they probably would have realized similar gains in income and relative bargaining power even without a move (Antel, 1980; DaVanzo \& Hosek, 1981). Moreover, in general, only realized migration and employment opportunities were recorded; therefore, the changes in threat points or the losses of household gains due to forgone opportunities are unknown. Conflicts and reasons for separation are difficult to assess with ordinary survey data and require paired information from both partners that is often not provided. An additional problem arises from the high correlation between employment characteristics and gender. Observed asymmetric decisions and outcomes may have arisen only because the labor market conditions created better returns for the male partner and not because his career concerns were fostered to a greater extent (Jacobson \& Levin, 2000).

For these reasons, we adopted a research approach that uses a factorial survey design (also known as vignette analysis). The key idea in this design is that the respondents react to hypothetical descriptions of situations or objects (i.e., vignettes) instead of answering single-item questions (see Jasso, 2006; Rossi \& Anderson, 1982). By independently varying a restricted number of dimensions of the vignettes in an experimental design, the exact impact of each dimension on respondents' judgments or decisions can be estimated. Therefore, the method is able to isolate the weight of single factors that are often confounded in reality. It is possible to separate the impact of gender and employment prospects by offering the same mobility incentives to male and female partners. The random allocation of vignettes leads to an overall independence of migration incentives and thereby overcomes the selection biases that limit the results of usual migration research.

In our study, we used vignettes to describe various incentives for a household move. As an innovation to the vignette design we interviewed 
Figure 1. Example of a Vignette (Male Perspective, OWn Job Offer).

\begin{abstract}
Assume, ...
You are offered a net salary of EUR $\underline{2,400}$ at the new location. In the long run, the new job will provide you with no advancement opportunities. If you don't move, commuting to the new job will take $1 \frac{1 / 2}{2}$ hours each way. It is possible to go there only by car.
\end{abstract}

Your partner's chances of finding a job at the new location are small and her income prospects are higher there compared to the local labor market.

How much would you like to take the job and move to the new location?

$\begin{array}{ccccccccccccc}\text { Not at } & 1 & 2 & 3 & 4 & 5 & 6 & 7 & 8 & 9 & 10 & 11 & \text { Very } \\ \text { all } & \square & \square & \square & \square & \square & \square & \square & \square & \square & \square & \square & \text { much }\end{array}$

\footnotetext{
Note: The inverse situation for the female partner in this example would read: Assume, your partner is offered a net salary of EUR 2,400 at the new location.... Your own chances of finding.... How much would you like to move to the new location?
}

both partners in dual-earner couples with inverse situations. Both partners were presented with the same set of situations, but one (ego) was given the role of a mover, and the other (alter) was put in the position of a tied mover. The constant stimulus consisted of a job offer for ego in another geographical region that provided the couple similar living conditions. The varying dimensions simulated differently attractive employment prospects in this new location for the two partners. This design allowed us to study the reactions to changing threat points in the relationship by varying the respective employment options. More concretely, we systematically varied (a) the increase in income and career prospects for the mover and (b) the employment and income prospects for the tied mover. By conducting computer assisted personal interviews (CAPI), we were able to simulate the income prospects as a percentage gain of the actual salary, which makes the situations as plausible as possible. To test our hypotheses, we assumed that ego's increase in income and career prospects improves his or her bargaining power in the relationship, whereas alter's employment prospects in the new destination affects the anticipated change in the bargaining power of ego's partner.

Concerning this assumption, two points are noteworthy. First, we manipulated the threat points of each partner independently, so it was possible that both actors' outside options would increase because of the move and that the relative bargaining in the partnership would not change. Thereby, our design had the advantage that alter might have profited from the move and was not restricted to the role of the tied mover. Second, we assumed that the employment situations of both actors determined bargaining power. Especially if one actor is engaged in highly specialized paid work, whereas the other is mostly engaged in housework, this assumption may be problematic. To address this problem, we restricted our sample to dual-earner couples. Figure 1 gives an example of the vignettes and shows the answer scale employed in this article. The vignettes also described the commuting time and the commuting mode (train or car) to the new destination to make the situations as realistic as possible. We used these variables as controls. Within a couple, both partners confronted the same hypothetical situations. The vignettes were identical, except one of the partners (ego) responded as the partner who received a job offer, whereas the other (alter) responded as the partner who did not receive the offer.

Our dependent variables were each partner's willingness to move and the conflict potential in a partnership that results from the migration incentive. The willingness to move scale scored from $1=$ not at all to $11=$ very much . The mirror-inverted design of our study allowed us to directly compare the alter's and ego's willingness to move for each vignette and to measure the conflict potential by taking the difference between ego's and alter's willingness to move. The resulting variable ranged from $-10=$ alter would very much like to move but ego does not want to move at all to $10=$ ego would very much like to move but alter does not want to move at all. A score of 0 indicated that both partners shared the same tendency for a move regardless of the strength of that preference. We treated all dependent variables as 
Figure 2A. Willingness to MOVE OF Ego AND Alter.
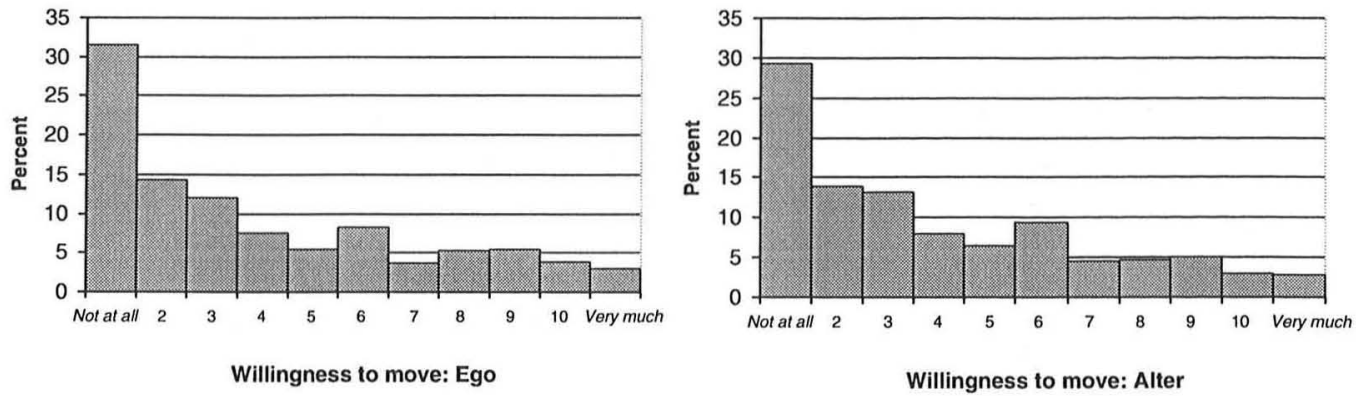

Figure 2B. Conflict Potential (Willingness to Move of Ego Minus Willingness to Move of Alter).

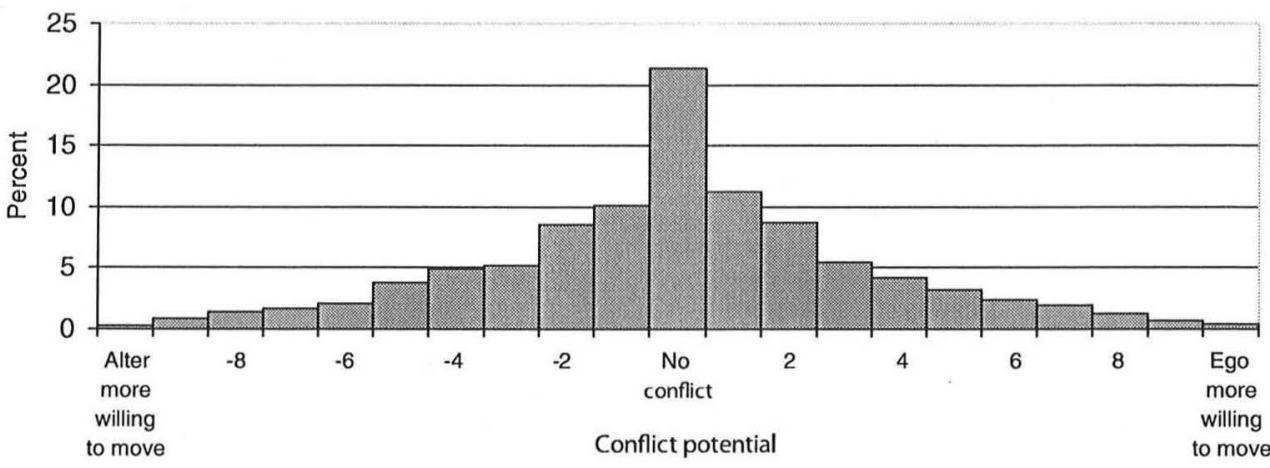

Note: In the regression analysis, we employed the absolute values of the conflict potential.

continuous. Several alternative statistical models for noncontinuous variables (e.g., ordinal regressions, Poisson regressions) did not yield different results; therefore, we used the more straightforward interpretation of an ordinary least squares (OLS) model. Because each person evaluated up to 10 different vignettes, the models had to be corrected for correlated observations, as is the case with any repeated measures in withinsubject designs (Hox, Kreft, \& Hermkens, 1991). We applied random intercept models (Raudenbush \& Bryk, 2001; Snijders \& Bosker, 1999) that account for dependent observations by estimating one joint random intercept for all observations from one single respondent or couple. The characteristics of the vignettes varied on Level 1, and either individual or couple characteristics were modeled as Level 2 variables.

The used sample of 200 vignettes was a fraction of all possible combinations of the six variable dimensions (maximization of the D-efficiency with orthogonalization of all main effects and first-order interactions in a so-called Resolution III, according to Kuhfeld, 2005; Kuhfeld, Randall, \& Garratt, 1994). Ten vignettes were presented to each person; that is, we used 20 different decks of vignettes and 80 different questionnaires $(20$ decks $\times 2$ versions for mover vs. tied mover $\times 2$ versions for men vs. women).

All interviews were conducted with couples living in Germany and Switzerland. Both countries represent conservative welfare regimes with gendered labor market participation rates, high occupational gender segregations, and gender pay gaps. For instance, in 2007 in Germany, only $64 \%$ of women between 15 and 64 years of age were employed compared to $75 \%$ of men; the overall gender pay gap was 23\% (European Commission, 2009). In both countries, traditional gender role beliefs are persistent (Stickney \& Konrad, 2007, p. 807). 


\section{RESULTS}

\section{Descriptive Results and Sample Description}

First, we provide a brief overview of some descriptive results for our nearly 280 interviewed couples. Only heterosexual couples were included in the sample to address the hypotheses about gender and to reach a higher standardization of the sample. Two universities (Konstanz and Bern) collaboratively conducted the research project using the CAPI method. The sample was selected by the network contacts of our 60 interviewers. For the research target at hand, a convenient sample seemed adequate because the central requirement was a random allocation of the experimental stimuli to the respondents. This procedure guaranteed the independence of the vignettes' and respondents' characteristics that was crucial for a strict test of our hypotheses. For example, it ensured the independence of migration incentives from the respondents' attributes and therefore prevented the selectivity bias of nonexperimental survey data on migrations. To restrict interviewer effects, the recruitment was restricted to an average of seven couples per interviewer. All interviews were conducted between June 2007 and February 2008. Independently, both partners in a couple responded to the vignettes and provided some basic information about themselves and the partnership. This was guaranteed throughout by the presence of an interviewer who prevented mutual consultations. We oversampled couples without children living in their household (such couples represented nearly $90 \%$ of our sample) to gain adequate variance in the willingness to move; children are often seen as a strict obstacle to migration. Similarly, the sample was restricted to salaried employees living in one joint household on a daily basis (no commuting or long-distance relationships) because of the well-known fact that self-employed persons and older people are especially immobile (on Germany, see Jürges, 2005). Moreover, we wanted to simulate a real decision-making dilemma by eliminating the desire to establish a joint household as an incentive to move.

An interesting observation is that $32 \%$ of all egos reported zero willingness to move, although the minimum gain was a $30 \%$ higher income (see Figure 2). Obviously, income prospects were not the only determinant of migration decisions. This finding is in line with the general low tendency to move, as reported in the migration literature
(Taylor, 2007). A further result worth noting is that in about $39 \%$ of the vignettes, alter was more willing to move than ego (the partner who actually got the job offer).

Table 1 presents descriptive data for the dependent variable and the sample. Because the vignettes' characteristics were all a direct result of our experimental plan, they always occurred with about the same frequency. The vast majority of our respondents were between 20 and 45 years old. All respondents were employed for at least 19 hours per week. The vast majority was employed full-time, and only $13 \%$ were employed fewer than 35 hours per week.

\section{Test of the Hypotheses}

Our first two hypotheses (1a and 1b) were tested using the analyses of ego's and alter's individual willingness to move. Table 2 shows the results of a random intercept model that controls for the individual variables. Negative coefficients indicate a lower willingness to migrate as the independent variable increases. The effects found in Models 1 and 2 implicate that both ego and alter showed a higher tendency to move as the employment conditions at the destination improved. Moreover, the data support our first hypothesis: Actors considered their partner's incentives in addition to their own incentives. Ego was more willing to move as alter's employment and income prospects improved at the new destination, and vice versa, alter showed a higher willingness to move as ego's migration gain increased. Because of the experimental, standardized design, we could compare the coefficients of alter and ego directly. An incentive to move for either partner was more relevant for the person who would profit from it than was the same incentive for his or her partner. For example, many career prospects for ego (compared to none) increased ego's willingness to move by an amount of 0.91 but alter's willingness to move only by an amount of 0.76 . In contrast, alter's willingness to move was influenced more strongly by his or her own better income prospects (1.60) than by ego's willingness to move $(0.87)$. Both ego and alter took their partners' situation into account but gave their own hypothetical gains more weight than their partners' throughout.

An interesting finding is that female egos displayed a lower willingness to move as compared to male egos (for similar results, 
Table 1. Sample Description

\begin{tabular}{|c|c|c|c|c|c|}
\hline & $N$ & Range & Mean & $S D$ & Median \\
\hline \multicolumn{6}{|l|}{ Dependent variables } \\
\hline \multicolumn{6}{|l|}{ Willingness to move } \\
\hline Ego & 2,772 & $1-11$ & 3.90 & 3.04 & 3 \\
\hline Alter & 2,770 & $1-11$ & 3.91 & 2.93 & 3 \\
\hline Potential for conflicts (absolute value) & 2,762 & $0-10$ & 2.55 & 2.38 & 2 \\
\hline \multicolumn{6}{|l|}{ Vignettes' characteristics } \\
\hline Gain of income for ego (\%) & 2,780 & $30-70$ & 49.82 & 14.07 & 50 \\
\hline \multicolumn{6}{|l|}{ Career prospects for ego (ref.: none) } \\
\hline Some & 2,780 & $0-1$ & .34 & .47 & \\
\hline Many & 2,780 & $0-1$ & .32 & .47 & \\
\hline Commuting time (hours) & 2,780 & $0.75-3.0$ & 1.62 & 0.79 & 1.5 \\
\hline Only reachable by car & 2,780 & $0-1$ & .48 & .50 & \\
\hline \multicolumn{6}{|l|}{ Employment prospects for alter (ref.: little) } \\
\hline Moderate & 2,780 & $0-1$ & .32 & .47 & \\
\hline Good & 2,780 & $0-1$ & .33 & .47 & \\
\hline \multicolumn{6}{|c|}{ Income prospects for alter at destination (ref:: smaller) } \\
\hline Equal & 2,780 & $0-1$ & .33 & .47 & \\
\hline Better & 2,780 & $0-1$ & .33 & .47 & \\
\hline \multicolumn{6}{|l|}{ Respondents' characteristics } \\
\hline Female respondent & 556 & $0-1$ & .50 & & \\
\hline Age & 547 & $20-50$ & 30.93 & 4.97 & 30 \\
\hline Duration of employment (months) & 551 & $0-360$ & 61.96 & 58.03 & 45 \\
\hline Duration of residence (years) & 552 & $0-45$ & 20.33 & 11.70 & 24 \\
\hline Net income (euros) ${ }^{\mathrm{a}}$ & 555 & $360-5,014$ & $1,935.61$ & 865.32 & 1,750 \\
\hline Propensity to lose the actual job ${ }^{b}$ & 555 & $1-11$ & 3.15 & 2.49 & 2 \\
\hline University graduate & 556 & $0-1$ & .44 & .50 & \\
\hline \multicolumn{6}{|l|}{ Households' characteristics } \\
\hline Living in Switzerland & 278 & $0-1$ & .23 & .42 & \\
\hline Real estate property & 278 & $0-1$ & .25 & .43 & \\
\hline Married couple & 278 & $0-1$ & .35 & .48 & \\
\hline Duration of partnership (months) & 278 & $2-325$ & 88.03 & 56.79 & 78 \\
\hline Children living in household & 277 & $0-1$ & .12 & .33 & \\
\hline $\begin{array}{l}\text { Married, long duration of partnership and } \\
\text { children in household }\end{array}$ & 277 & $0-1$ & .08 & .27 & \\
\hline \multicolumn{6}{|l|}{ Education ${ }^{c}$} \\
\hline Male partner has higher education & 278 & $0-1$ & .32 & .47 & \\
\hline Female partner has higher education & 278 & $0-1$ & .29 & .45 & \\
\hline \multicolumn{6}{|l|}{ Income $^{d}$} \\
\hline Male partner has higher income & 277 & $0-1$ & .77 & .42 & \\
\hline Female partner has higher income & 277 & $0-1$ & .17 & .38 & \\
\hline \multicolumn{6}{|l|}{$\mathrm{Age}^{\mathrm{e}}$} \\
\hline Male partner is older & 269 & $0-1$ & .44 & .50 & \\
\hline Female partner is older & 269 & $0-1$ & .06 & .23 & \\
\hline
\end{tabular}

${ }^{a}$ Net income: adjusted for the different purchasing power in Switzerland and Germany. ${ }^{b}$ Propensity to lose the actual job: scored from 1 =very unlikely to $11=$ very likely. ${ }^{\mathrm{c}}$ Education: $0=$ spouses have the same education, $1=$ male or female spouse has higher education (at least 1 year more schooling). ${ }^{\mathrm{d}}$ Income: $0=$ the monthly net income of the two spouses differ by less than 100 euros, $1=$ male or female partner has at least 100 euros more income. ${ }^{\mathrm{e}} \mathrm{Age}: 0=$ the age difference is less than three years, 1 = male or female partner is at least 3 years older than his or her spouse. 
Table 2. Summary of Linear Regression Analysis for Variables Predicting the Willingness to Move (Random Intercept

\begin{tabular}{|c|c|c|c|c|}
\hline \multicolumn{5}{|c|}{ Models) } \\
\hline & \multicolumn{2}{|c|}{$\begin{array}{l}\text { Model 1: Own } \\
\text { Job Offer (Ego) }\end{array}$} & \multicolumn{2}{|c|}{$\begin{array}{l}\text { Model 2: Partner Gets } \\
\text { Job Offer (Alter) }\end{array}$} \\
\hline & $B$ & $S E B$ & $B$ & $S E B$ \\
\hline \multicolumn{5}{|l|}{ Vignettes' characteristics } \\
\hline Gain of income for ego $(10 \%)$ & $0.30^{* * *}$ & 0.03 & $0.23^{* * *}$ & 0.03 \\
\hline \multicolumn{5}{|l|}{ Career prospects for ego (ref. none) } \\
\hline Some & $0.74^{* * *}$ & 0.10 & $0.45^{* * *}$ & 0.10 \\
\hline Many & $0.91^{* * *}$ & 0.10 & $0.76^{* * *}$ & 0.10 \\
\hline Commuting time (hours) & -0.03 & 0.05 & $-0.17^{* *}$ & 0.05 \\
\hline Only reachable by car (ref.: also by train) & 0.00 & 0.08 & -0.07 & 0.08 \\
\hline \multicolumn{5}{|l|}{$\begin{array}{l}\text { Employment prospects for alter at } \\
\text { destination (ref.: little) }\end{array}$} \\
\hline Moderate & $0.45^{* * *}$ & 0.10 & $0.84^{* * *}$ & 0.10 \\
\hline Good & $1.03^{* * *}$ & 0.10 & $1.98^{* * *}$ & 0.10 \\
\hline \multicolumn{5}{|l|}{$\begin{array}{l}\text { Income prospects for alter at destination } \\
\text { (ref.: smaller in comparison with the } \\
\text { actual destination) }\end{array}$} \\
\hline Equal & $0.52^{* * *}$ & 0.10 & $0.67^{* * *}$ & 0.10 \\
\hline Better & $0.87^{* * *}$ & 0.10 & $1.60^{* * *}$ & 0.10 \\
\hline \multicolumn{5}{|l|}{ Respondents' characteristics } \\
\hline Interview conducted in Switzerland & -0.01 & 0.38 & 0.02 & 0.32 \\
\hline Female respondent & $-0.80^{* *}$ & 0.29 & 0.11 & 0.25 \\
\hline Age & -0.06 & 0.03 & -0.04 & 0.03 \\
\hline Duration of residence & -0.02 & 0.01 & $-0.03^{*}$ & 0.01 \\
\hline Real estate property & $-1.13^{* *}$ & 0.33 & $-0.64^{*}$ & 0.29 \\
\hline University graduate & 0.41 & 0.31 & 0.23 & 0.28 \\
\hline Duration of employment (10 years) & 0.02 & 0.03 & -0.01 & 0.02 \\
\hline Net income $(1,000 \text { euros })^{a}$ & 0.28 & 0.20 & -0.10 & 0.18 \\
\hline Propensity to lose the actual job & $0.14^{* *}$ & 0.05 & $0.11^{*}$ & 0.05 \\
\hline Constant & $2.56^{*}$ & 1.01 & $2.72^{* *}$ & 0.89 \\
\hline Observations & \multicolumn{2}{|c|}{2,704} & 2,671 & (268 interviewees) \\
\hline Variance & & & & \\
\hline$\sigma_{v}$ & $2.02^{* * *}$ & 0.10 & $1.69^{* * *}$ & 0.08 \\
\hline$\sigma_{\varepsilon}$ & 1.95 & 0.03 & 1.97 & 0.03 \\
\hline
\end{tabular}

Note: Gray shading marks vignette variables directly concerning the employment prospects of the respondent (instead of those of his or her partner).

${ }^{a}$ Adjusted for the different purchasing power in Switzerland and Germany.

${ }^{*} p<.05,{ }^{* *} p<.01,{ }^{* * *} p<.001$.

see Baldridge, Eddleston, \& Veiga, 2006; Bielby \& Bielby, 1992). Without controlling for the absolute income level of male and female respondents, this difference was even greater (results not displayed). A reason for this observation may be that women prefer a shorter distance from their home to their place of employment (McLafferty \& Preston, 1997) and rely on social support from relatives and other networks when they have children or when they anticipate their family obligations in the future. As a consequence, they may be more reluctant to leave a carefully constructed work arrangement (Kalleberg \& Rosenfield, 1990). Employment opportunities for better pay may be less beneficial for women because it may be difficult to achieve the same kind of balance between household responsibilities 
and employment responsibilities in a new job. We return to this when we present models differentiated by gender.

As for the other individual determinants, our results are mostly in line with previous findings from survey research on migration. People tended to be less mobile when they owned real estate property (Deane, 1990) or as the time lived in one place increased (Baldridge et al., 2006; Jürges, 2005). The respondents' actual employment characteristics, education level, and current network embeddedness, however, did not have a significant influence on the willingness to move. This may be the result of effects working in opposite directions: A higher education level may, for example, lead to better earning prospects at the actual destination and increase the potential gains of migration. Because these variables served only as controls, we refrained from deeper analyses.

Taken together, the outcomes from the individual models are mainly consistent with previous results based on migration research and provide strong evidence for our first hypothesis.

We next examined our hypothesis regarding the conflict potential. It was measured as difference between ego's and alter's willingness to move and hence represents a variable at the couple level. Table 3 presents the results of a random intercept model that includes partnership-level variables at Level 2. For ease of interpretation, we used the absolute values of the conflict potential as dependent variable; greater values always indicate a greater disagreement in interests, whoever is more willing to move. Therefore, a positive (negative) regression coefficient indicates an increase (decrease) of the conflict potential as the respective variable increases.

Starting with ego's mobility incentives, an interesting observation is that, as income and employment prospects improved, the potential for conflicts also increased. This result is consistent with our second hypothesis: A one-sided increase in bargaining power will raise the difference in interests and, as a result, the conflict potential. Because of the characteristics of a multivariate regression analysis, the effect in question is indeed one sided because we controlled for alter's bargaining power in the multivariate analysis. It is also exactly that aspect that makes sense of alter's results that appear to be similarly counterintuitive. Alter's improving income and employment prospects increased the conflict potential. Because the indicators of the partner's bargaining power were always kept constant by the multiple regression models, we could interpret any actor's changes in employment prospects as one sided. Furthermore, bargaining theory is very clear on this point. If alter's (ego's) incentive to move increases and ego's (alter's) incentive stays constant, we should observe a higher conflict, and the findings sustain this pattern. Consequently, the data support our core hypothesis, $\mathrm{H} 2$.

For the third hypothesis, we have to look at partnership characteristics. We assumed that knowledge about each other and the level of commitment might be variables that counteract the conflict potential. Models 1-4 in Table 3 present the individual effects of the four relevant variables: marriage, children, and estate property as indicators of commitment and duration of the partnership as an indicator of learning and commitment. The results mainly support our hypotheses. The conflict potential decreased if a couple was married, had children, or owned real estate and decreased as the length of the relationship increased. The existence of a marriage and children showed the expected negative influence on the conflict potential, but both effects failed to reach statistical significance. In the full Model 5, the effects of the variables were all still negative but no longer significant. A possible explanation for this may be the relatively homogenous sample with high correlations of these partnership attributes (e.g., marriage and partnership were correlated at .45). Even with a random sample and more cases, it would be difficult to disentangle the effects because of an underlying mechanism: Marriage and children make a partnership more stable, and couples with a longer common history are more likely to marry and to become parents. To avoid potential multicollinearity, we compared an extreme group (couples that were married, had a long partnership duration, and had children) with the rest of our sample. Long duration was defined by more than 6.5 years and applied to about half of our sample. The results presented in Model 6 support our hypothesis that these determinants, especially in combination with one another, are associated with less conflict potential in a partnership.

The variables indicating homogeneity of education, income, and age in Models 5 and 6 served as controls for different compositions of relationships. In the bargaining literature, the actors who possess more of these resources 
Table 3. Summary of Linear Regression Analysis for Variables Predicting the Potential of Conflicts (Random Intercept Models)

\begin{tabular}{|c|c|c|c|c|c|c|c|c|c|c|c|c|}
\hline & \multicolumn{2}{|c|}{ Model 1} & \multicolumn{2}{|c|}{ Model 2} & \multicolumn{2}{|c|}{ Model 3} & \multicolumn{2}{|c|}{ Model 4} & \multicolumn{2}{|c|}{ Model 5} & \multicolumn{2}{|c|}{ Model 6} \\
\hline & $B$ & $S E B$ & $B$ & $S E B$ & $B$ & $S E B$ & $B$ & $S E B$ & $B$ & $S E B$ & $B$ & $S E B$ \\
\hline \multicolumn{13}{|l|}{ Vignettes' characteristics } \\
\hline Gain of income for ego $(10 \%)$ & $0.14^{* * *}$ & 0.03 & $0.14^{* * *}$ & 0.03 & $0.14^{* * *}$ & 0.03 & $0.14^{* * *}$ & 0.03 & $0.15^{* * *}$ & 0.03 & $0.15^{* * *}$ & 0.03 \\
\hline \multicolumn{13}{|l|}{ Career prospects for ego (ref.: none) } \\
\hline Some & 0.11 & 0.10 & 0.12 & 0.10 & 0.11 & 0.10 & 0.11 & 0.10 & 0.12 & 0.10 & 0.12 & 0.10 \\
\hline Many & $0.32^{* *}$ & 0.10 & $0.31^{* *}$ & 0.10 & $0.31^{* *}$ & 0.10 & $0.31^{* *}$ & 0.10 & $0.34^{* *}$ & 0.10 & $0.34^{* *}$ & 0.10 \\
\hline Commuting time (hours) & -0.06 & 0.05 & -0.06 & 0.05 & -0.07 & 0.05 & -0.07 & 0.05 & -0.07 & 0.05 & -0.07 & 0.05 \\
\hline Only reachable by car (ref.: also by train) & 0.05 & 0.08 & 0.05 & 0.08 & 0.06 & 0.08 & 0.06 & 0.08 & 0.05 & 0.08 & 0.05 & 0.08 \\
\hline \multicolumn{13}{|l|}{$\begin{array}{l}\text { Employment prospects for alter at } \\
\text { destination (ref.: little) }\end{array}$} \\
\hline Moderate & 0.10 & 0.10 & 0.11 & 0.10 & 0.10 & 0.10 & 0.10 & 0.10 & 0.12 & 0.10 & 0.13 & 0.10 \\
\hline Good & $0.51^{* * *}$ & 0.10 & $0.52^{* * *}$ & 0.10 & $0.51^{* * *}$ & 0.10 & $0.51^{* * *}$ & 0.10 & $0.52^{* * *}$ & 0.10 & $0.51^{* * *}$ & 0.10 \\
\hline \multicolumn{13}{|l|}{$\begin{array}{l}\text { Income prospects for alter (ref.: smaller in } \\
\text { comp. with actual location) }\end{array}$} \\
\hline Equal & $0.23^{*}$ & 0.10 & $0.24^{*}$ & 0.10 & $0.23^{*}$ & 0.10 & $0.23^{*}$ & 0.10 & $0.24^{*}$ & 0.10 & $0.24^{*}$ & 0.10 \\
\hline Better & $0.64^{* * *}$ & 0.10 & $0.65^{* * *}$ & 0.10 & $0.64^{* * *}$ & 0.10 & $0.64^{* * *}$ & 0.10 & $0.65^{* * *}$ & 0.10 & $0.66^{* * *}$ & 0.10 \\
\hline \multicolumn{13}{|l|}{ Couples' characteristics } \\
\hline Married couple & -0.31 & 0.17 & & & & & & 0.03 & 0.21 & -0.00 & 0.20 & \\
\hline Children living in household & & -0.48 & 0.25 & & & & -0.49 & 0.28 & & & & \\
\hline Real estate property & & & & $-0.51^{* *}$ & 0.19 & & $-0.4^{*}$ & 0.21 & $-0.49^{*}$ & 0.20 & & \\
\hline Duration of partnership (10 months) & & & & & & $-0.04^{* *}$ & 0.01 & -0.02 & 0.02 & & & \\
\hline $\begin{array}{l}\text { Married, long duration of partnership \& } \\
\text { children in household }{ }^{\mathrm{a}}\end{array}$ & & & & & & & & & & $-0.76^{*}$ & 0.33 & \\
\hline \multicolumn{13}{|l|}{ Education (ref.: same education) } \\
\hline Male partner has higher education & & & & & & & & -0.19 & 0.20 & -0.14 & 0.20 & \\
\hline Female partner has higher education & & & & & & & & -0.25 & & 0.20 & -0.22 & 0.20 \\
\hline \multicolumn{13}{|l|}{ Income (ref.: same income) ${ }^{b}$} \\
\hline Male partner has higher income & & & & & & & & 0.31 & 0.37 & 0.30 & 0.37 & \\
\hline Female partner has higher income & & & & & & & & 0.49 & 0.41 & 0.47 & 0.41 & \\
\hline Age (ref.: same age) ${ }^{c}$ & & & & & & & & & & & & \\
\hline
\end{tabular}


(education, income, and age) as compared to their partners are often considered to be more powerful. For example, a higher age indicates, in general, a higher advancement of occupational careers (Halleröd, 2005). Job-related migrations are, however, assumed to be more financially rewarding for younger people because of the longer time span left for labor market payoffs (Becker, 1993). Hence, any increase in the age difference between partners should increase the conflict potential regarding migrations. We found a significantly higher conflict potential only in Model 6 and in those partnerships where the male partner was at least 3 years older than his female partner. That we did not observe corresponding results for the partnerships in which the female partner was older may be the consequence of the small number of those couples in our sample; only $6 \%$ fell into this category (see again Table 1). Similarly, the high homogeneity of our sample and the high tendency of positive assortative mating lead to small variances in the education and income differences between the partners and may explain why the variables did not have strong effects.

In addition, we tested several interaction effects of the career and employment prospects of the two partners to find out whether the conflict potential was dampened if both partners had good opportunities at the destination. The regression estimates, which are not displayed but are available on request, revealed that the interaction terms mainly showed the expected negative effects on the conflict potential but failed to reach significance.

Finally, we focused on possible gender effects. To test H4, which states that male employment characteristics have a stronger effect on the willingness to move than female employment characteristics, we estimated separate models for male and female respondents. The results shown in Table 4 do not provide very strong support for gendered evaluations of the vignettes. Comparing the results for men with the results for women in Model 1 (ego) and Model 2 (alter), the gender gap was, in general, in line with the hypothesis but not statistically significant. We analyzed overall differences between men and women by using Chow tests (Wooldridge, 2003) and the difference of single variables by interaction terms with gender, estimating in each case a joint model for male and female respondents. There was only one significant difference for alters (Model 2): 
The coefficient for egos' career prospects was significantly higher in the case of female alters than in the case of male alters. This means that women in the position of alter valued the career options related to their partners' job options more than men did. Further analyses (not presented here) demonstrated that the overall results were similar when we controlled for differences in age, education, and income in partnerships. The evaluation, therefore, seemed to not be influenced by actors' actual relative power within the partnership. Thus, the evidence regarding $\mathrm{H} 4$ was mixed overall: A female ego's willingness to move in general was lower (see Table 2), but the impact of incentives did not vary much by gender. Only alter's willingness to move was more influenced by ego's employment opportunities when alter was the female instead of male partner.

\section{DISCUSSION}

The goal of this article was twofold. We attempted to shed light on the influence of both partners' job opportunities in migration decisions within dual-earner households, and we proposed a new way to test bargaining theory in family research. On the basis of a factorial survey of about 280 European couples, we demonstrated that there is a substantial potential for conflicts in a partnership when work-related incentives for a move arise. As predicted, the conflict potential in a couple varied according to each partner's change in relative bargaining power. Moreover, we found clear evidence that couples were able to minimize this conflict through mutual commitment and knowledge of each other (measured by the duration of partnership). Hence, our data support the bargaining model. In addition, we found little evidence for the relevance of gender regarding the influence of bargaining power on the individual willingness to move. This result has to be treated cautiously because couples without children are oversampled in our data, and couples with children tend to develop a more gendered division of labor (Baxter, Hewitt, \& Haynes, 2008). Even though we found only slight evidence for gendered decisions, these might in some constellations already be sufficient to trigger a continuously widening of the career gap between men and women because-from a bargaining point of view-subsequent career and migration decisions will especially promote the career of the more successful and therefore powerful spouse.

An important limitation of our study is that we observed only hypothetical decisions and no real actions. It is still unclear to what extent factorial surveys produce valid results (Eifler, 2007). Fortunately, much research evaluating similar methods (conjoint analysis and stated choice experiments) exists. This research showed, all in all, an astonishingly high correspondence of hypothetical and experimental decisions with real observations (Blamey \& Bennett, 2001; Louviere, Hensher, \& Swait, 2000). Moreover, there was evidence that the willingness to move is a feasible predictor of actual relocation behavior (Brett \& Reilly, 1988). In addition, further analyses of migration behavior in Germany found that variables such as real estate property and occupational characteristics have a similar impact on the willingness to move reported in the analyses on hand and on real migration propensity measured with the German Socio-Economic Panel (Nisic \& Auspurg, 2009). Thus, we do not have any major reason to doubt the overall external validity of our results.

Another critical aspect is the occurrence of a social desirability bias. The sensitivity of factorial surveys for those effects in general is controversial. In our case, the risk seems minor because we did not ask very sensitive questions. Social desirability should, by definition, intensify the measured relevance of norms. That we observed only weak evidence for gendered norms is, therefore, a hint for the robustness of our results, even if social desirability cannot be completely excluded. Regarding the convenience sample, we encourage replications of our design with other sampling techniques.

Another direction for future research would be a test of the supposition that the actors anticipate future allocations. This could be done by additional answer scales that question the anticipated share of resources or even obligations (e.g., housework tasks) in the case where a household move has taken place. Gender dynamics underlying the decision-making processes not visible through the quantitative data on hand might be addressed by combining vignette analyses with qualitative interviews (Ganong \& Coleman, 2006).

In general, the results of our study emphasize the relevance of a couple- or household-oriented approach when labor market processes are studied. Individual career mobility is often directly 
Table 4. Summary of Linear Regression Analysis for Variables Predicting the Willingness to Move of Men and Women (Random Intercept Models)

\begin{tabular}{|c|c|c|c|c|c|c|c|c|}
\hline \multirow[b]{3}{*}{ Variable } & \multicolumn{4}{|c|}{ Model 1: Own Job Offer (Ego) } & \multicolumn{4}{|c|}{ Model 2: Partner Gets Job Offer (Alter) } \\
\hline & \multicolumn{2}{|c|}{ Men } & \multicolumn{2}{|c|}{ Women } & \multicolumn{2}{|c|}{ Men } & \multicolumn{2}{|c|}{ Women } \\
\hline & $B$ & $S E B$ & $B$ & $S E B$ & $B$ & $S E B$ & $B$ & $S E B$ \\
\hline Gain of income for ego $(10 \%)$ & $0.35^{* * *}$ & 0.04 & $0.25^{* * *}$ & 0.04 & $0.22^{* * *}$ & 0.04 & $0.27 * * *$ & 0.04 \\
\hline \multicolumn{9}{|l|}{ Career prospects for ego (ref. none) } \\
\hline Some & $0.85^{* * *}$ & 0.14 & $0.57^{* * *}$ & 0.14 & 0.20 & 0.14 & $0.66^{* * *}$ & 0.15 \\
\hline Many & $0.90^{* * *}$ & 0.14 & $0.84^{* * *}$ & 0.14 & $0.67^{* * *}$ & 0.14 & $0.85^{* * *}$ & 0.14 \\
\hline Commuting time (hours) & 0.08 & 0.07 & $-0.14^{*}$ & 0.07 & $-0.21^{* *}$ & 0.07 & $-0.15^{*}$ & 0.07 \\
\hline $\begin{array}{l}\text { Only reachable by car (ref.: also by } \\
\text { train) }\end{array}$ & 0.08 & 0.11 & -0.12 & 0.11 & -0.02 & 0.11 & -0.09 & 0.12 \\
\hline $\begin{array}{l}\text { Employment prospects for alter at } \\
\text { destination (ref.: little) }\end{array}$ & & & & & & & & \\
\hline Moderate & $0.51^{* * *}$ & 0.14 & $0.33^{*}$ & 0.14 & $0.82^{* * *}$ & 0.13 & $0.78^{* * *}$ & 0.14 \\
\hline Good & $1.09^{* * *}$ & 0.14 & $0.86^{* * *}$ & 0.14 & $1.83^{* * *}$ & 0.13 & $2.06^{* * *}$ & 0.14 \\
\hline \multicolumn{9}{|l|}{$\begin{array}{l}\text { Income prospects for alter (ref: } \\
\text { smaller in comp. with actual } \\
\text { location) }\end{array}$} \\
\hline Equal & $0.53^{* * *}$ & 0.13 & $0.55^{* * *}$ & 0.13 & $0.62^{* * *}$ & 0.13 & $0.62^{* * *}$ & 0.14 \\
\hline Better & $0.92^{* * *}$ & 0.13 & $0.90^{* * *}$ & 0.14 & $1.61^{* * *}$ & 0.13 & $1.51^{* * *}$ & 0.14 \\
\hline Constant & 0.68 & 0.37 & $1.35^{* * *}$ & 0.37 & $1.17^{* *}$ & 0.36 & $0.92^{*}$ & 0.36 \\
\hline Observations & \multicolumn{2}{|c|}{1,438} & \multicolumn{2}{|c|}{1,334} & \multicolumn{2}{|c|}{1,336} & \multicolumn{2}{|c|}{1,434} \\
\hline (Interviewees) & \multicolumn{2}{|c|}{$(144)$} & \multicolumn{2}{|c|}{$(134)$} & \multicolumn{2}{|c|}{$(134)$} & \multicolumn{2}{|c|}{$(144)$} \\
\hline Variance & & & & & & & & \\
\hline$\sigma_{v}$ & $2.36^{* * *}$ & 0.15 & $1.99^{* * *}$ & 0.13 & $1.82^{* * *}$ & 0.12 & $1.84^{* * *}$ & 0.12 \\
\hline$\sigma_{\varepsilon}$ & 1.99 & 0.04 & 1.92 & 0.04 & 1.90 & 0.04 & 2.05 & 0.04 \\
\hline
\end{tabular}

Note: In this regression analysis, only vignettes' characteristics were included. Gray shading marks variables concerning the male partner. Coefficients in bold indicate significant differences between men and women.

${ }^{*} p<.05,{ }^{* *} p<.01,{ }^{* * *} p<.001$.

linked to regional mobility, and we have shown that new individual career options for one partner create potential conflicts in the relationship. Cooperative solutions require balanced power shifts or, at the least, credible commitment to the partnership. The scope of this finding is probably not restricted to migration decisions because the same theoretical mechanism can be assumed for other issues such as fertility decisions. Without solutions to the conflicts connected with choices that asymmetrically change the employment prospects of the partners and therefore shift their balance of bargaining power, suboptimal levels of family welfare will arise (Jürges, 2005; Ott, 1992).

At least in our sample of European dualearner couples, the responses to the incentives for regional moves differed only slightly by gender. Apart from the fact that women tended to be more resistant to moving than their male partners, we found gender roles to be less obviously important than has often been stated. The high prevalence of tied women reported in the literature seems to result more from their inferior labor market positions than from traditional gender roles in the household. We found that both male and female partners take their respective partner's perspective into account, and they did it mostly in the same way. In a more general view, this means that the efforts to achieve greater gender equality in the labor market and in families go hand in hand. Better career prospects for women and more balanced (migration) decisions presuppose each other.

\section{REFERENCES}

Antel, J. J. (1980). Returns to migration: Literature review and critique. Santa Monica, CA: RAND. 
Baldridge, D. A., Eddleston, K. A., \& Veiga, J. F. (2006). Saying "no" to being uprooted: The impact of family and gender on willingness to relocate. Journal of Occupational and Organizational Psychology, 79, 131- 149.

Bartel, A. P. (1982). Wages, nonwage job characteristics, and labor mobility. Industrial and Labor Relations Review, 35, 578-589.

Baxter, J., Hewitt, B., \& Haynes, M. (2008). Life course transitions and housework: Marriage, parenthood, and time on housework. Journal of Marriage and Family, 70, 259-272.

Becker, G. S. (1993). Human capital: A theoretical and empirical analysis with special reference to education. Chicago: University of Chicago Press.

Bergstrom, T. C. (1996). Economics in a family way. Journal of Economic Literature, 34, 1903 - 1934.

Bernasco, W., \& Giesen, D. (2000). A bargaining approach to specialization in couples. In J. Weesie \& W. Raub (Eds.), The management of durable relations: Theoretical models and empirical studies of households and organizations (pp. 42-43). Amsterdam: Thela Thesis.

Bielby, W. T., \& Bielby, D. D. (1992). I will follow him: Family ties, gender-role beliefs, and reluctance to relocate for a better job. American Journal of Sociology, 97, 1241-1267.

Bitman, M., England, P., Folbre, N., Sayer, L., \& Matheson, G. (2003). When does gender trump money? Bargaining and time in household work. American Journal of Sociology, 109, 186-214.

Blackburn, Mc. K. L. (2006). The impact of internal migration on married couples' earnings in Britain, with a comparison to the United States (ISER Working Paper 2006-24). Essex, UK: Institute for Social and Economic Research.

Blamey, R., \& Bennett, J. (2001). Yea-saying and validation of a choice model of green product choice. In J. Bennett \& R. Blamey (Eds.), The choice modeling approach to environmental valuation (pp. 179-201). Cheltenham, UK: Elgar.

Blau, F., Ferber, M. A., \& Winkler, A. E. (2001). The economics of women, men, and work. Englewood Cliffs, NJ: Prentice Hall.

Blood, R. O., \& Wolfe, D. M. (1960). Husbands and wives: The dynamics of married living. Glencoe, IL: Free Press

Brett, J. M., \& Reilly, A. H. (1988). On the road again: Predicting the job transfer decision. Journal of Applied Psychology, 73, 614-620.

Brines, J., \& Joyner, K. (1999). The ties that bind: Principles of cohesion in cohabitation and marriage. American Sociological Review, 64, 333-355.

Cooke, L. P. (2006). "Doing" gender in context: Household bargaining and risk of divorce in Germany and the United States. American Journal of Sociology, 112, 442-472.

DaVanzo, J., \& Hosek, J. R. (1981). Does migration increase wage rates? An analysis of alternative techniques for measuring wage gains to migration. Santa Monica, CA: RAND.

Deane, G. D. (1990). Mobility and adjustment: Paths to the resolution of residential stress. Demography, $27,65-79$.

Eifler, S. (2007). Evaluating the validity of selfreported deviant behavior using vignette analyses. Quality and Quantity, 41, 303-318.

England, P., \& Farkas, G. (1986). Households, employment, and gender: A social, economic, and demographic view. New York: Aldine.

European Commission. (2009). Report on equality between women and men 2009. Luxembourg: Office for Official Publications of the European Communities.

Fenstermaker, S. (2002). Work and gender. In S. Fenstermaker \& C. West (Eds.), Doing gender, doing difference: Inequality, power, and institutional change (pp. 105-114). New York: Routledge.

Ganong, L. H., \& Coleman, M. (2006). Multiple segment factorial vignette design. Journal of Marriage and Family, 68, 455-468.

Halleröd, B. (2005). Sharing of housework and money among Swedish couples: Do they behave rationally? European Sociological Review, 21, $273-288$

Hook, J., \& Chalsani, S. (2008). Gendered expectations? Reconsidering single fathers' child-care time. Journal of Marriage and Family, 71, 978-990.

Hox, J. J., Kreft, I., \& Hermkens, P. (1991). The analysis of factorial surveys. Sociological Methods and Research, 19, 493-510.

Huppe, M., \& Cyr, M. (1997). Division of household labor and marital satisfaction of dual income couples according to family life cycle. Canadian Journal of Counseling, 31, 145-162.

Jacobson, J. P., \& Levin, L. M. (2000). The effects of internal migration on the relative economic status of women and men. Journal of Socio-Economics, 29, $291-304$.

Jasso, G. (2006). Factorial survey methods for studying beliefs and judgments. Sociological Methods and Research, 34, 334-423.

Jürges, H. (2005). Gender ideology, division of housework, and the geographic mobility of families. Review of Economics of the Household, 4, 299-323.

Kalleberg, A. L., \& Rosenfield, R. A. (1990). Work in the family and in the labor market: A crossnational, reciprocal analysis. Journal of Marriage and the Family, 52, 331-346.

Klasen, S. (1998). Marriage, bargaining, and intrahousehold resource allocation: Excess female mortality among adults during early German development, 1740-1860. Journal of Economic History, 58, $432-467$. 
Kuhfeld, W. F. (2005). Marketing research methods in SAS: Experimental design, choice, conjoint and graphical techniques. Cary, NC: SAS Institute.

Kuhfeld, W. F., Randall, T. D., \& Garratt, M. (1994). Efficient experimental design with marketing research applications. Journal of Marketing Research, 31, 545-557.

Lichter, D. (1983): Socioeconomic returns to migration among married women. Social Forces, 62, $487-503$

Louviere, J. L., Hensher, D. A., \& Swait, J. D. (2000). Stated choice methods: Analysis and application. Cambridge, UK: Cambridge University Press.

Lundberg, S., \& Pollak, R. A. (1996). Bargaining and distribution in marriage. Journal of Economic Perspectives, 10, 139-158.

Lundberg, S., \& Pollack, R. A. (2003). Efficiency in marriage. Review of Economics of the Household, 1, $153-167$.

Manser, M., \& Brown, M. (1980). Marriage and household decision-making: A bargaining analysis. International Economic Review, 21, 31 - 44.

Maxwell, N. (1988). Economic returns to migration: Marital status and gender differences. Social Science Quarterly, 69, 108-121.

McHugh, K. E., Gober, P., \& Reid, N. (1990). Determinants of short- and long-term mobility: Expectations for home owners and renters. Demography, 27, $81-95$.

McLafferty, S., \& Preston, V. (1997). Gender, race, and the determinants of commuting: New York in 1990. Urban Geography, 18, 192-212.

Miller, R. S., Perlman, D., \& Brehm, S. S. (2007). Intimate relationships. Boston: McGraw-Hill.

Mincer, J. (1978). Family migration decisions. Journal of Political Economy, 86, 749-773.

Nisic, N., \& Auspurg, K. (2009). Faktorieller Survey und klassische Bevölkerungsumfrage im Vergleich-Validität, Grenzen und Möglichkeiten beider Ansätze. In P. Kriwy \& C. Gross (Eds.), Klein aber Fein! Quantiative empirische Sozialforschung mit kleinen Fallzahlen (pp. 211-246). Wiesbaden: VS-Verlag für Sozialwissenschaften.
Nock, S. L. (1995). Commitment and dependency in marriage. Journal of Marriage and the Family, 57, $503-514$.

Ott, N. (1992). Intrafamily bargaining and household decisions. Berlin: Springer.

Quigley, J. M., \& Weinberg, D. H. (1977). Intraurban residential mobility: A review and synthesis. International Regional Science Review, 2, 41 - 66.

Raudenbush, S. W., \& Bryk, A. S. (2001). Hierarchical linear models: Applications and data analysis methods. Thousand Oaks, CA: Sage.

Rossi, P. H., \& Anderson, A. B. (1982). The factorial survey approach: An introduction. In P. H. Rossi \& S. L. Nock (Eds.), Measuring social judgments: The factorial survey approach (pp. 15-67). Beverly Hills, CA: Sage.

Shauman, K. A., \& Noonan, M. C. (2007). Family migration and labor force outcomes: Sex differences in occupational context. Social Forces, 85, $1735-1764$

Snijders, T. A., \& Bosker, R. J. (1999). Multilevel analysis: An introduction to basic and advanced modeling. London: Sage.

Spitze, G. (1984). The effect of family migration on wives' employment: How long does it last? Social Science Quarterly, 65, 21-36.

Stickney, L. T., \& Konrad, A. M. (2007). Gender-role attitudes and earnings: A multinational study of married women and men. Sex Roles, 57, 801-811.

Szinovacz, M., \& Harpster, P. (1993). Employment status, gender role attitudes, and marital dependence in later life. Journal of Marriage and the Family, 55, 927-940.

Taylor, M. P. (2007). Tied migration and subsequent employment: Evidence from couples in Britain. Oxford Bulletin of Economics and Statistics, 69, $795-818$.

Thibaut, J. W., \& Kelley, H. H. (1959). The social psychology of groups. New York: Wiley.

West, C., \& Zimmerman, D. H. (1987). Doing gender. Gender and Society, 1, 125-151.

Wooldridge, J. M. (2003). Introductory econometrics: A modern approach. Mason, $\mathrm{OH}$ : Thomson. 